during the War, and problems involved in industrial lighting and in the lighting of homes of the future.

A dinner took place at the Connaught Rooms on the evening of May 15, when the principal guest was the Right Hon. George Tomlinson, Minister of Works. On the evening of May 16, members were the guests of the General Electric Co. Ltd. at Magnet House where an amusing burlesque pageant "Lighting through the Ages" and an 'opera' containing many topical allusions were staged. A visit to the National Physical Laboratory on the morning of May 17 completed the programme.

\section{MATHEMATICAL FILMS}

A VERY successful meeting arranged by the London Branch of the Mathematical Association and the Pure Science Committee of the Scientific Film Association took place on May 18 at the Polytechnic, Regent Street, London.

The first film shown presented the Euclidean proof of Pythagoras' Theorem; there seemed to be little advantage in using the film to replace the coloured chalks and the suitable dissections of the figure which would be used by any experienced teacher. The next, on the differential equation $x^{\prime \prime}+x=0$, was not immediately convincing; but a second or third viewing, and a study of the accompanying notes, might make it useful as a 'working model', which was the plan of the producers. On the other hand, the film on the generation of involute gears was quite impressive on first seeing, as was another on the generation of Lissajous figures by the combination of simple harmonic motions. The last of this series illustrated hypocyclic motion and contained several interesting sequences. These films were produced by Mr. R. A. Fairthorne and Mr. B. G. D. Salt, who are the most active of the British producers.

"Rate of Change", produced by Mr. A. D. Segaller, was next shown; in it the differential coefficient was introduced as the slope of the distance-time curve for a motor-car. There followed a French film, "Mouvements vibratoires", which again showed the combination of two simple harmonic motions, and then moving and standing waves on a string. The final item was an American Kodak production on frequency distributions, in which the passage from the histogram to the frequency curve was illustrated in the case of the distribution of the diameters of grains in photographie emulsion.

There is no doubt that the art of the cinematographer has some part to play in the teaching of mathematics; but where that part is and how it should be played is not yet very clear. Several bodies are examining these questions at the moment and this revival of older films will be valuable in the clarification of some of the problems involved. It should now be possible, with more time and perhaps more funds available, to arrange planned studies of the use of films in mathematical teaching. In particu. lar, attention could be paid to the various computing mechanisms which have been developed for firecontrol and navigational purposes during the last few years, and for some of which instructional films have been produced for Service use.

Whether the film should be used merely as a quickener of interest in the class-room, or whether it should make a more positive contribution in presenting realizations of the abstract topics under discussion, or whether it should be used in the actual exposition of the topics for which this medium is particularly suited-these are some of the questions which will have to be considered first. Then, a suitable topic for motion-picture presentation having been chosen, it is most important to decide beforehand the type of audience to which the film will be shown. Perhaps it will be found that the greatest value to be obtained is in the actual making of films, and this is an activity which can be recommended to clubs and societies at schools, colleges and universities. There are many topics at hand and, in particular, attention might be paid to three-dimensional problems, as has already been done in the United. States.

\section{GREENLAND PROBLEMS}

TN spite of difficulties in recent years, a number of important monographs on different aspects of Greenland have been published in the series Meddelelser om Grönland (København: C. A. Reitzel). "Survey of North Greenland", by L. Koch (Medd., 130 , No. 1, 1940), is a historical and cartographical review in English of all work in northern Greenland, and particularly Peary Land, since the days of the Franklin search.

One of its most important sections is the discussion of the existence of the so-called Peary Channel, which in 1892 Peary claimed to have discovered as separating the ice-clad Greenland to the south from the ice-free Peary Land. This stretched between Nordenskjold's Fjord on the west and Independence Fjord on the east. Peary did not carry out subsequent plans for its exploration but turned his attention farther north. M. Erichsen failed to find it, and K. Rasmussen in 1919 doubted its existence; but L. Koch in 1921 found that Brönland's Fjord, on the north of Independence Fjord, was continued far to the west in a depression, Wandelsdal, in which lies a lake, Midsommer Sjö, and in 1938 from the air he traced the continuance of this depression not to Nordenskjöld's Fjord but to the longer J. P. Koch's Fjord. Thus, he maintains that the Peary Channel is re-established, not far from the position in which Peary placed it, even if it is not an arm of the sea.

Long before the ice-free Peary Land was discovered, arctic authorities postulated such an ice-free route as affording the only likely way by which the Eskimo could have reached the east coast of Greenland. The conditions of livelihood on the east coast and the scope for population are discussed in a long memoir in English by E. Mikkelsen in conjunction with P. P. Sveistrup entitled "The East Greenlanders" (Medd., 134$, No. $2 ; 1944)$. It is now believed that the Eskimo reached the east coast via both the north and the south, but the experiments in neither case seem to have been very successful. Eskimo coming by the northern route had a land-hunting economy, reindeer and musk-ox; those by the southern route a seahunting economy, seal and whale. There was more than one migration, at least from the south, between the beginning, about the fourteenth century, and the seventeenth century. From the extreme south to Danmark's Havn, the ruins of at least 1,228 houses have been found, some for five or six inhabitants, others for as many as thirty or forty; but when Europeans came in contact with East Greenland in the nineteenth century, the population was in steady decline. In 1829 it was estimated at 581, in 1892 at 
475. Then in 1895, Denmark founded at Angmagssalik the first trading station on the east coast in the only district with any considerable population; and in 1925 some of the population was transferred north to a new station on Scoresby Sound. The problem facing Denmark is that of maintaining an east coast population in view of the dwindling in the past, which seems to have been caused by both decrease of resources, especially whale and seal, and the attraction of the Danish settlements on the south-west where life offered more amenities and so lured the Eskimo from the east. Migration can be checked by the foundation of new Danish stations on the east, but on the other hand a station segregates population, which thus exhausts local hunting and depends more and more on imported food and unsuitable imported clothes. If the population is to survive, it must be induced to spread over wide hunting grounds, and those grounds do exist.

A third important monograph (Medd., 129, No. 1, 1944) is that by L. Bobé on Hans Egede, the Danish missionary who early in the eighteenth century founded Danish settlements in Greenland and threw light on the fate of the long-lost Norse colonization of Greenland. Old maps and pictures are reproduced.

\section{THE LOOKATOR}

$\mathrm{E}$ ECTRICAL echoes are known to occur within telephone lines wherever there are impedance irregularities, and it was upon this principle that the 'lookator' was developed for locating faults on telephone lines (J. T. Schott, Bell Lab. Rec., 23, No. 10, October 1945).

The principle employed is to measure the time for an electrical pulse to travel from some reference point of measurement out to a fault and return in the form of a reflected pulse to the reference point. Knowing the speed of transmission of the pulse over the particular circuit, the distance to the fault can be obtained. In practice, the time is determined automatically by the equipment.

The 'lookator' consists of an oscillator, an initialzero adjusting circuit, a pulse generator, a hybrid coil with its associated adjustable balancing notwork, a receiving circuit, a measuring circuit, a sweop circuit, and a cathode-ray tube with associated control circuits. Keys are provided for testing and talking on either a two- or four-wire basis. The bridge-stabilized 220-cycle oscillator feeds through the zero-adjusting circuit into the pulse generator, where the oseillator frequency controls the rate at which the pulses are generated. The pulses, having individually the approximate shape of a positive lobe of a 3 -kc. $\sin \theta$ wave, are delivered to the line through a hybrid coil and a set of keys. The balancing network forms part of the hybrid-coil circuit, and may be adjusted to balance any line impedances likely to be encountered.

The outgoing pulses travel along the line to the impedance irregularity caused by a fault. They are here reflected, and return along the line to the 'lookator', where they enter the receiving amplifier, and appear as a vertical deflexion on the screen of the cathode-ray tube. A second output of the oscillator feeds through the measuring circuit into the sweep circuit, where it controls the frequency of the horizontal sweep. The zero-adjusting circuit and the measuring eircuit permit the phase of the voltage supplied to the pulse generator and sweep circuits of the 'lookator' to be controlled individually. Consequently, the time at which functions in the sending and sweep circuits take place can be adjusted as desired with respect to each other. Since the oseillator frequency is fixed, a measure of the phase difference between the A.c. voltages controlling the electrical events in the two circuits will be a measure of the time required for the pulse to travel from the 'lookator' to the fault and back again. It is then possible to prepare a curve showing the relationship between time in arbitrary scale divisions and the distance out to known points on a particular facility.

In addition to its primary purpose as a fault locator, the 'lookator' can be used for many other purposes such as general laboratory testing, for adjusting networks properly to balance lines, for adjusting line terminations, for observing short-time changes in the height of the ionosphere, and, in its present form, for indicating the presence of large cross-talk coupling and showing approximately where the irregularity responsible for the cross-talk is located.

\section{FORTHCOMING EVENTS}

Tuesday, June 11

ZOOLOGICAL SOCIETY OF LONDON (at Regent's Park, London, N.W.8), at 5 p.m.-Scientiflc Papers.

Friday, June 14

RoYal Institution (at 21 Albemarle Street, London, W.1), at 5.15 p.m.-Capt. W. W. Davis : "Torpedoes, their Use and Development during the War".

Tuesday, June II-Friday, June 14

MANChester UNIVERSITY (in the Physics Department), at 4.30 p.m. each day.-Dr. Max Delbrück (of Vanderbilt University, Tennessee) : "Problems of Modern Biology in relation to Atomic Physics".

\section{Saturday, June 15}

Institute of Physics, ELECTRONics Group (in the Research Laboratories of the General Electric Co., Wembley), at 2.30 p.m.Prof. N. F. Mott, F.R.S., Dr. G. F. J. Garlick and Mr. L. C. Jesty).

\section{APPOINTMENTS VACANT}

APPLICATIONS are invited for the following appointments on or before the dates mentioned :

RESEARCH ASSISTANT IN THE VETERINARY LABORATORY of the Agricultural Department-The Registrar, King's College, Newcastle. upon-Tyne (June 15).

Mathematician to take charge of the work done on the Bush machine (differential analyser) and Mallock machine in the Mathemachine (differential analyser) and Mallock machine in the Mathe-

TEAcHER (full-time) OF CHEMISTRY - The Principal and Secretary, TEACHER (full-time) OF CHEMISTR

ASSISTANT LECTURER IN ZOOLOGY-The Registrar, University AssisTANT LECTURER IN
College, Leicester (June 15).

LECTURER (Grade II), and an AssisTaNT LECTURER (Grade III),

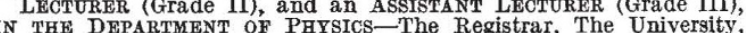
Liverpool (June 15).

Liverpool (June 15). LECTURER IN GLASSHOUSE CROPS AND COMMERCIAL FLOWER-
GROWING-The Principal, Midland Agricultural College, Sutton GROWING-The Principal, Midland

Bonington, Loughborough (June 15).

AssISTANT CHEMrST at the River Avon Waterworks-The Water Engineer and Manager, Spon House, 21 Allesley Old Road, Coventry (June 17).

ASSISTANT LECTURER IN THE DEPARTMENT OF BOTANY-The Secretary, King's College, Strand, London, W.C.2 (June 17)

METEOROLOGICAL OFFICER CADETS (15), Department of Industry and Commerce, Dublin-The Secretary, Civil Service Commission, 45 Upper O'Connell Street, Dublin (June 18).

PERMANENT ASSISTANT SECRETARY-The Secretaries, Royal Astronomical Society, Burlington House, Piccadilly, London, W.1. June 29).

Leoturer in Mathematicar Physics (including Applied Mathematics) in the Department of Natural Philosophy-The Secretary, The University, Aberdeen (June 30).

MICROBIOLOGIST in the Cider Section, and a RESEARCH AssistanT IN MYcologx, at the Long Ashton Research Station-The Secretary and Registrar, The University, Bristol 8 (June 30). 